The University of Akron

\title{
IdeaExchange@UAkron
}

Proceedings from the Document Academy

University of Akron Press Managed

December 2014

\section{An (Un)session: A Copy of a Fake of the Identical Facsimile Reproduced from the Real Original}

Kiersten F. Latham

Kent State University, Kent OH, USA, kflatham@kent.edu

Corina M. Iannaggi

Kent State University - Kent Campus, ciannagg@kent.edu

Please take a moment to share how this work helps you through this survey. Your feedback will be important as we plan further development of our repository.

Follow this and additional works at: https://ideaexchange.uakron.edu/docam

Part of the Scholarly Communication Commons

\section{Recommended Citation}

Latham, Kiersten F. and Iannaggi, Corina M. (2014) "An (Un)session: A Copy of a Fake of the Identical Facsimile Reproduced from the Real Original," Proceedings from the Document Academy: Vol. 1 : Iss. 1 , Article 5.

DOI: https://doi.org/10.35492/docam/1/1/5

Available at: https://ideaexchange.uakron.edu/docam/vol1/iss1/5

This Conference Proceeding is brought to you for free and open access by University of Akron Press Managed at IdeaExchange@UAkron, the institutional repository of The University of Akron in Akron, Ohio, USA. It has been accepted for inclusion in Proceedings from the Document Academy by an authorized administrator of

IdeaExchange@UAkron.For more information, please contact mjon@uakron.edu, uapress@uakron.edu. 


\section{Introduction, or, What is this article about?}

This article is about a single session at the 2014 Document Academy conference (DOCAM). It is about the content of the session, but also the way in which the session was structured and conducted.

In the spirit of the recent "unconference" trend, we (Latham \& Iannaggi) led an "unsession" to explore our topic at the 2014 Document Academy. The unconference format, applicable to any professional gathering, allows the people in the audience-not just those selected to speak on stage - to share thoughts, insights, and expertise (Follett, 2006) in a flexible and fluid approach to professional knowledge-sharing. This structure (or lack of) allows idea-sharing, networking, demonstrating, learning, and creating with others (Follett, 2006; Greenhill \& Wiebrands, 2008). The point of the unconference is to provide a forum for participants "to discuss what they want, when they want" (Greenhill \& Wiebrands, 2008, 2). Activities and outcomes are very open and emergent and proceed by following the direction participants take with the topic at hand.

Perhaps not so ironically, our (un)session topic-about representation and all its forms - itself came about in an emergent way. It was during a meeting of our local, informal group centered around document studies, the Kent/Akron Document Club, on a trip to the Cleveland Museum of Art (Ohio, USA) to see a van Gogh exhibit entitled "Repetitions." This exhibit was focused on van Gogh's practice of painting multiple similar versions of his own compositions, and combined a technical analysis of the paintings, "with a close reading of his letters to offer a deeper understanding of how and why he produced the works he called répétitions," (Robinson, 2014, p.4). After our group toured the exhibition, we sat down in the museum's café to discuss a small section from Buckland's 1991 book, Information and Information Systems titled, "Copies of Information and Representations" (1991, pp. 52-54). Great debate and conversation ensued about the meanings of copies, how they differ from replicas, "Xeroxes", and in particular, digital versions of some thing. The conversation became intense around Buckland's example of mass-produced telephones. As Buckland states: 
The feature of equally acceptable copies is sometimes (but not always found) in other examples of information systems. Some sorts of museum objects are mass-produced, such as telephones. With telephones as with printed books, one example is as acceptable as any other from the same production run. There is, however a major qualification. In archival practice, as in museums, two physically identical documents may be regarded as different if they have a different provenance or have some special relationship to other items in the collection...

In other words, each individual, mass-produced telephone could have a different life history (Wood \& Latham, 2013).

From that conversation, the members of the Document Club thought it would be interesting to bring our conversation to the larger, more geographically represented Document Academy, which was to be next held in Kent, and so two of us (Latham and Iannaggi) submitted a proposal. By design, we knew that we wanted the session to emulate the conversation that night at the museum and so we aimed to make it participatory, document-centered, and set up as to encourage input, discussion and debate from everyone who attended.

The remainder of this article will take us through three segments of the session: the plan (getting prepared), the (un)session (what actually happened), and the products (little documents, or "original copies").

\section{The Plan}

Before describing what we hoped to do with this session, we should first introduce the abstract accepted for the conference:

Every day people use words such as copy, original, real, fake, actual, true, identical and more in reference to documents and their various representations. In this session, we engage the audience through a handson activity involving the creation of "original copies". In addition, we will attempt to sort through some of this language in order to work towards a more intentional language surrounding this continuum of copies. We will provide scenarios in which we ask where on the continuum does a certain document fall; are some copies less of a copy than others; is the first document really that different from the second or third one; is there such a thing as identical copy (eg. Buckland's "token," 1991), how (why?) do certain copies attain higher value than others; is the experience of one type 
of document different than another? Generating a focused, common language of description may help address some of these questions and this session is meant to draw out a thoughtful, purposeful conversation about them (Latham \& Iannaggi, 2013).

From the beginning, we did not want this to be a traditional session. Our intent was to create and inspire interaction and co-creation of content. We did not want to present all the answers, but rather wished to join in a negotiation with others in our field about the language used to describe representations. In order to do this, we set up a few parameters to help move us along but left many openings, allowing the audience guide our path.

The (un)session was to be centered on a single document, a painting by Patric Fourshé, Latham's artist father. This painting (see Fig 1) is very largeabout 4'x4'-consisting of only four colors: red, black, white and green. We chose this painting because of its apparent simplicity in design and limited color palette. Our plan was to have each person in the audience to create their own version of this painting, their own "original copy." After this, we wanted the group to describe these representations that they just created, decide how we refer to them in both scholarly and everyday circles, and discuss the complex language used to denote the multiple layers of originals to copies. Table 1 outlines the basic plan we created to guide the session. 
Figure 1. Polar Shift II, painting by Patric Fourshé (pictured, K.F. Latham)

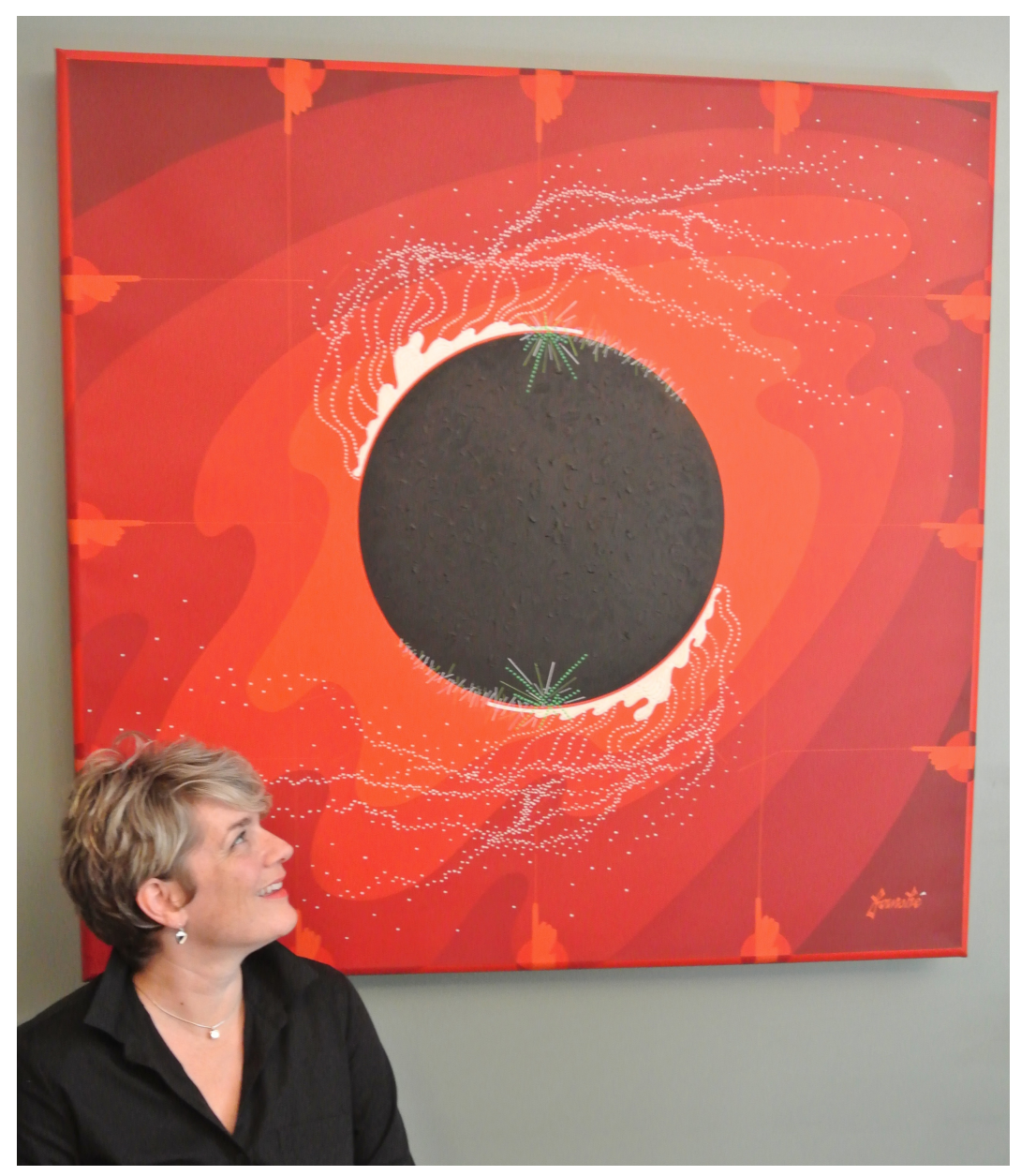


Table 1. The rough outline/plan of the session.

\begin{tabular}{|c|c|c|}
\hline Section & Activities & $\begin{array}{l}\text { Time } \\
\text { allotted } \\
\text { (minutes) }\end{array}$ \\
\hline Pre-session & $\begin{array}{l}\text {--Prepare whiteboard with a selection of words used } \\
\text { for representations and cover } \\
\text {--Prepare chalkboard with "continuum" framework } \\
\text { in preparation of activity and cover } \\
\text {--Prepare whiteboard with end questions and cover }\end{array}$ & $\mathrm{n} / \mathrm{a}$ \\
\hline Introduction & $\begin{array}{l}\text {--Present context and intentions to audience } \\
\text {--Pass out pre-cut red square paper and } \\
\text { "coloring" tools }\end{array}$ & 2 \\
\hline Activity & $\begin{array}{l}\text {--Give directions to audience for "coloring" activity } \\
\text {--Painting propped up so all can see } \\
\text {--Audience draws their versions and displays on } \\
\text { cork board }\end{array}$ & 6 \\
\hline $\begin{array}{l}\text { Continuum } \\
\text { Creation }\end{array}$ & $\begin{array}{l}\text {--Present blank continuum on chalkboard. } \\
\text {--Audience is invited to fill in words provided on } \\
\text { another white board, and to add ones that are } \\
\text { not present. } \\
\text {--Action: On chalkboard, write down what } \\
\text { audience says. } \\
\text {--Play RadioLab excerpt on the Swamp Man }\end{array}$ & 6 \\
\hline $\begin{array}{l}\text { Ask } \\
\text { Questions }\end{array}$ & $\begin{array}{l}\text {--Ask: } \\
\text { Does the continuum work? } \\
\text { If not, how else can we represent it? Do we need to? } \\
\text { How do we talk about these things? }\end{array}$ & 6 \\
\hline Afterwards & $\begin{array}{l}\text {-- Continue discussion about continuum and other } \\
\text { ways to represent the different meanings of } \\
\text { the words } \\
\text {-- Discussion at MuseLab Instantiation where } \\
\text { documents representing our session where } \\
\text { on exhibit } \\
\text {-- Post everyone's "original copy" of the painting on } \\
\text { display in lobby (where all other conference activity } \\
\text { took place) }\end{array}$ & $\mathrm{n} / \mathrm{a}$ \\
\hline
\end{tabular}


When the two of us (Latham and Iannaggi) first began brainstorming our session idea of copies, fakes, originals we felt that there had to be a way to sort through this spectrum of document representations and we generated a lot of questions about them. For example, are some copies less of a copy than others? And, how does one copy attain higher value than another? We decided to create preliminary textual and graphical ways to discuss the words used to describe these representations. First we put together a short list of words commonly used to describe different forms of documents (see Fig 2). We would begin with this list, presenting it to our audience during the session.

Figure 2. Words provided on whiteboard prior to session.

\section{True Copy Actual Authentic Reproduction Replica Representation Facsimile Real Type Token}

We then decided that in order to answer the questions that came up during the past Document Club meeting, we would need a device to help us work through all the complexity that arose. Even though we were unsure of how to do this, we plunged in and decided upon a continuum, with "Fake" on one end and "Original" on the opposing end (see Figure 3). Even determining which words to use on each end of the continuum was a struggle (albeit an interesting one) but we needed to settle on something in order to move forward in the session. Our intent was to use this continuum to get participants talking about what the words mean in the context of today's document-rich world. We told the participants that we were not claiming the continuum to be accurate, but as a way to spark thoughtful and directed conversation. 
Figure 3. The bare continuum, prior to audience participation.

\section{Fake----------------------------------Original}

\section{The (un)Session: What Actually Happened}

From the beginning, the presentation began to unfold in a way that was not planned in the basic outline. Once the drawing activity began, Latham told a story of the painting that led into a deeper discussion about how she came to acquire the painting, how it fits into a series of paintings on "maps," how she takes care of her father's paintings, and where they are stored. During this time, the participants asked questions - about the painting, about the activity, and about representations in general. Although it was not chaotic, there was a constant exchange as the audience engaged with us, the presenters (or perhaps, more correctly, the facilitators). As a result, the drawing period went beyond the allotted six minutes for the activity, so we had to refocus the conversation on the little documents and the continuum activity.

In addition, we presented the whiteboard list of words earlier than planned because participants began to ask about terminology. While people were still drawing, we invited anyone to come up to the board at will and add words that were not present. Markers were placed out and available for use. We were surprised by how many new words were being added.

When the drawing activity was done, we asked people to pass their "original copies" to us and we put them on the bulletin board at the front of the room so everyone could look over the results. This bulletin board was later moved to the lobby area for the remainder of the conference.

The next activity was to work on the continuum. We were prepared for this to be difficult because we were sure that the continuum was not the way to represent these words. Even so, it was hard to get any sort of consensus on their placement on the continuum, but there was a lot of engagement in the process. Suggestions were made about how to make the model better and participants came up to the chalkboard to draw out their ideas. One observation we made about the "results" on the chalkboard was that many words that we had discussed 
in our private planning as leaning more towards the "fake" end were being placed closer to the "original" end of the continuum (such as replica and facsimile) by the audience (see Figure 8). Unfortunately, due to time constraints, we had to cut this discussion short. Those who were particularly engaged in the conversation congregated at the chalkboard to further discuss their ideas for a different model after the session ended (luckily, we were scheduled just before a break).

After the presentation, we were pleased with the great conversation and input from everyone who attended the session. The response to the continuum and word selection activity was so interesting and thought-provoking that we soon realized we left out the RadioLab excerpt on the Swampman thought experiment. Introduced in a 1987 article by Davidson, a philosopher, the experiment goes something like this:

"Imagine, you are standing next to the swamp, you are you, and in the swamp is a bunch of bubbling gases - chemical reactions - bubbling and interacting in some weird organic way...but then, a bolt of lighting comes out of the sky and kills you. And then, another one comes out of the sky and hits the swamp, catalyzing all that chemistry into overdrive and somehow miraculously, for just a moment, the reactions come together in just the right way to form.... man - completely identical to [you]... if you took every single molecule in the swampman's body, it would be exactly like yours at this very moment." (Krulwich \& Abumrad, 2014)

The question is then asked, does swamp-you remember things from your childhood, last year, yesterday, moments ago? Does swamp-you care about the same things that you-you did? Are the memories and experiences of your life suddenly contained in that facsimile? While we were initially disappointed because we felt that the excerpt added another dimension to our presentation, we were happy with the overall positive feedback and response to the drawing and continuum activities.

\section{Products from the Session}

While everyone in the session (about 35 people) participated in the "coloring" activity, 26 "original copies" were collected as a result of the activity. In addition, we captured the outcomes of other activities written on the whiteboards and chalkboard while people were drawing and participating in the continuum work. 
In this article, we are only able to show a selection of the documents produced. Our presentation of these representations is not the result of a formal analysis, it is simply to provide an example of what was produced. The "original copies" ranged from highly "accurate" depictions (Figure 4) to abstract illustrations (Figure 5).

Figure 4. Original Copies, examples of highly "accurate" documents.

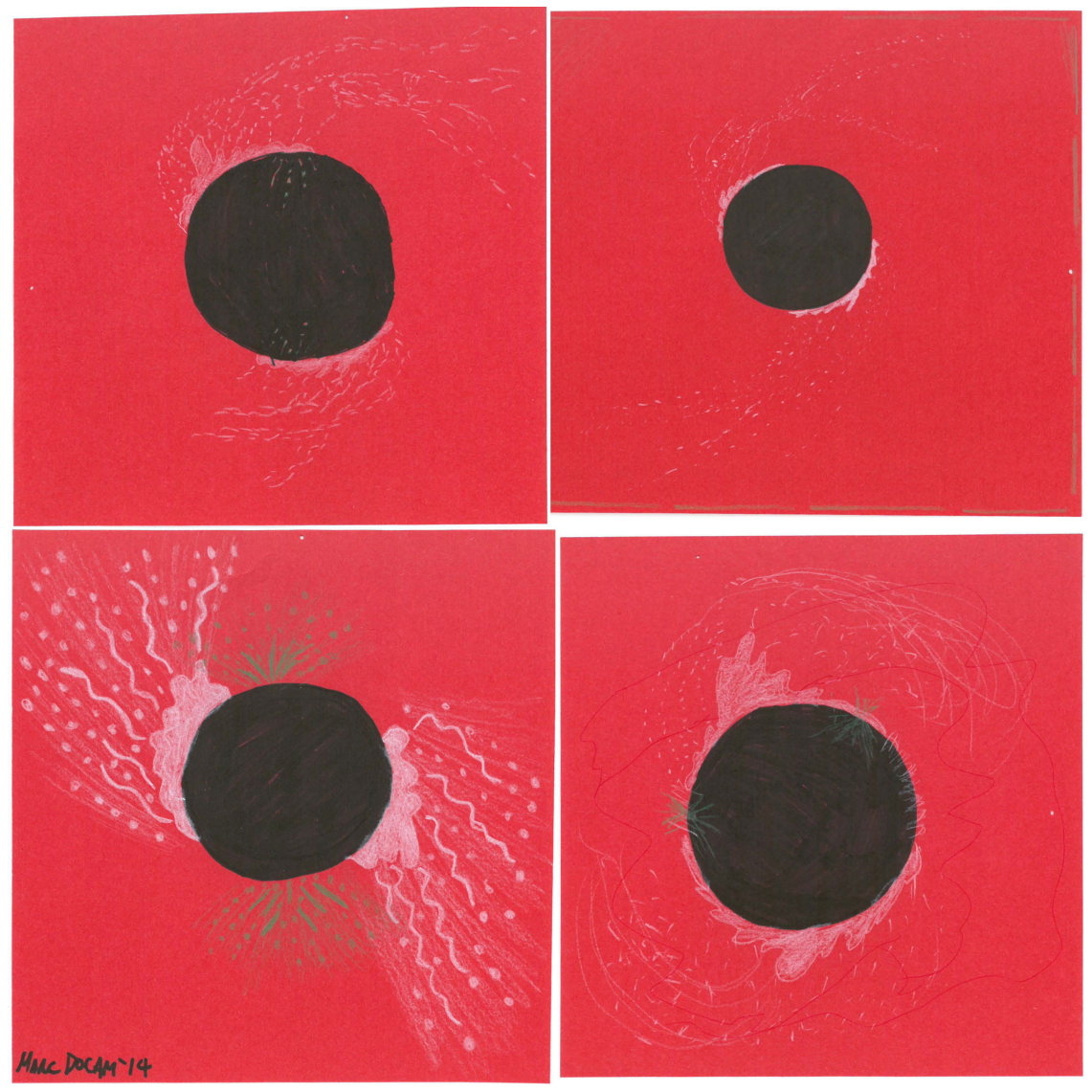


Figure 5. Original Copies, examples of abstract illustrations.
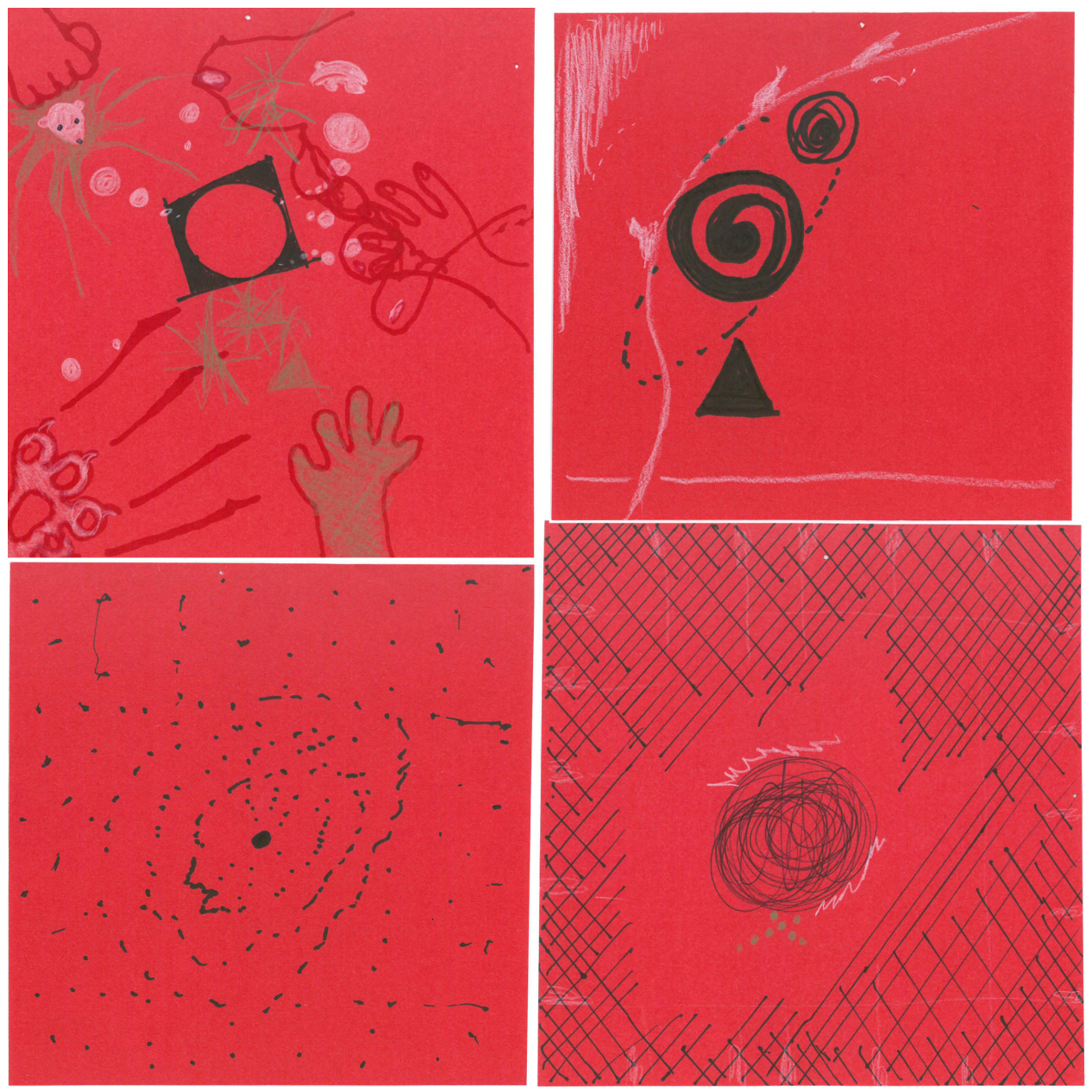

In one case, the little document that was created represented everything that happened in the session. Brian O'Connor, who was sitting at the back of the room, drew what he saw and heard on his little red square (see Figure 6). He captured a more holistic situation by drawing what was happening all at once from his perspective. This included his view of the people in the audience, the desks, the screen, the presenter speaking (Latham, who was providing background about her father's painting), a representation of words being spoken by Latham, and the Fourshé painting (as only a part of the scenario). He then captured this moment by taking a photograph. This document (his "original copy") is not only a representation of the painting, but of the presentation itself. 
Figure 6. Brian O'Connor's "original copy" and a photograph he took from that perspective about the same time.

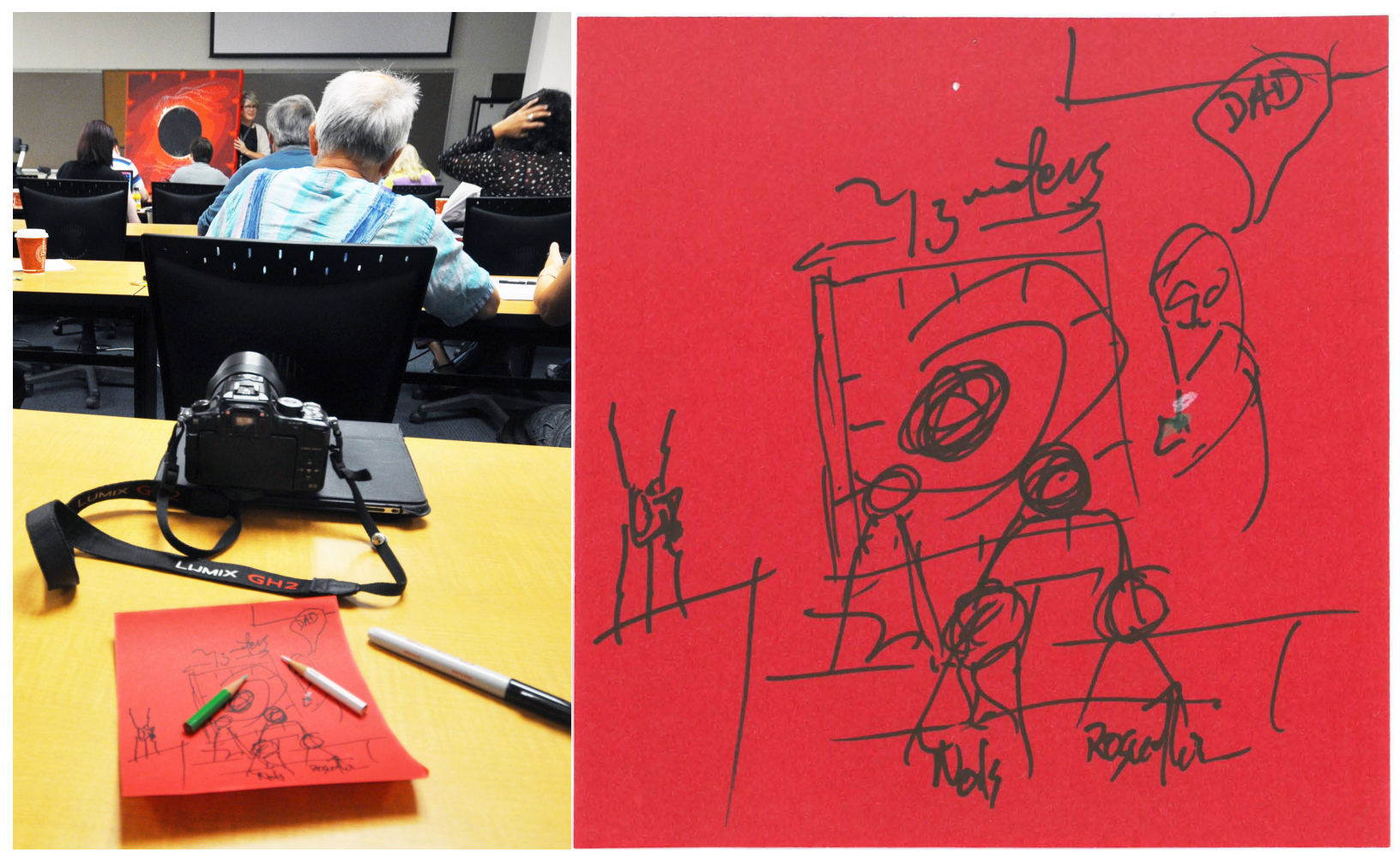

Another product of the (un)session was the filled-in white board full of words that we use to refer to representations (Figure 7). The audience was invited to come up and write ones they thought of throughout the session. The original words, written in capital letters, were what we provided at the start of the session. 
Figure 7. Photograph of words on whiteboard after session ended.

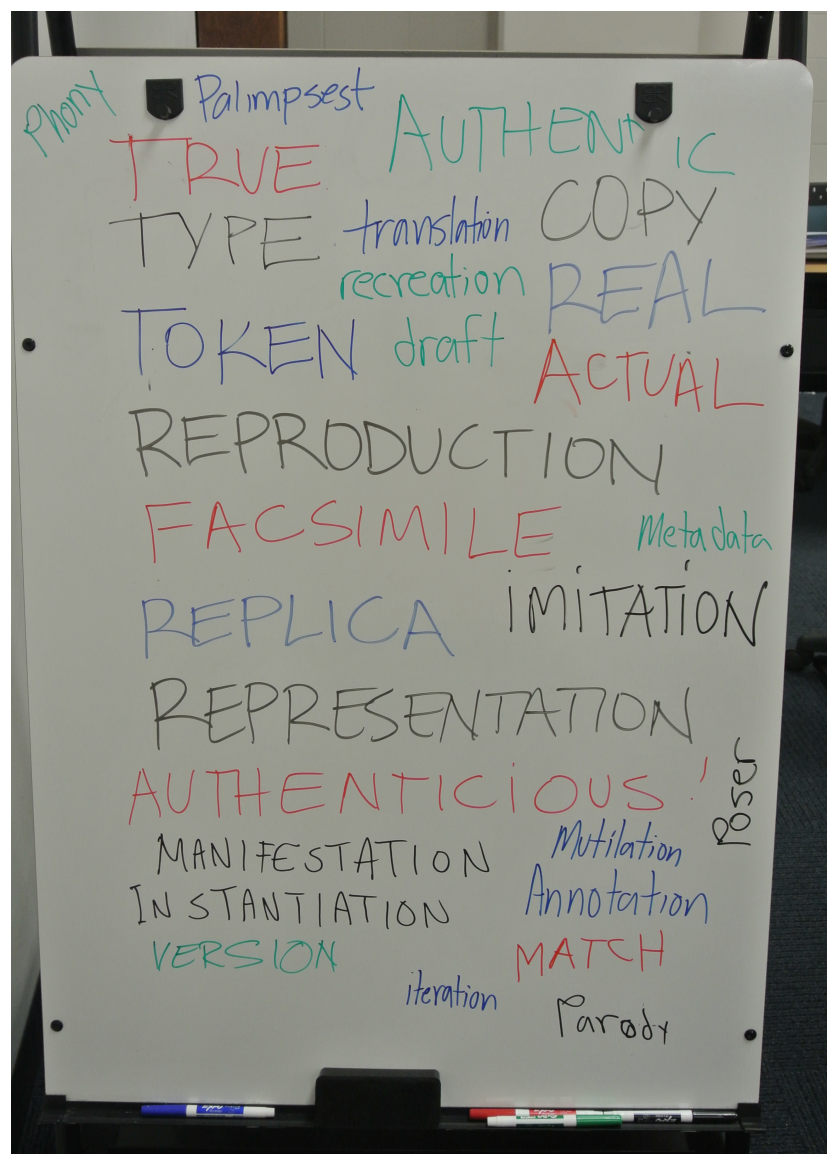

The continuum was the third product from the session. Although it was messy, it served its purpose. The outcome was far from "complete" (see Figure 8) but it allowed the audience to interact with the content, which was our goal at the outset. If we had had more time, a re-working of this graphical device (which was beginning to take place), with the audience would have been very interesting. 
Figure 8. Photograph of continuum work after session ended.

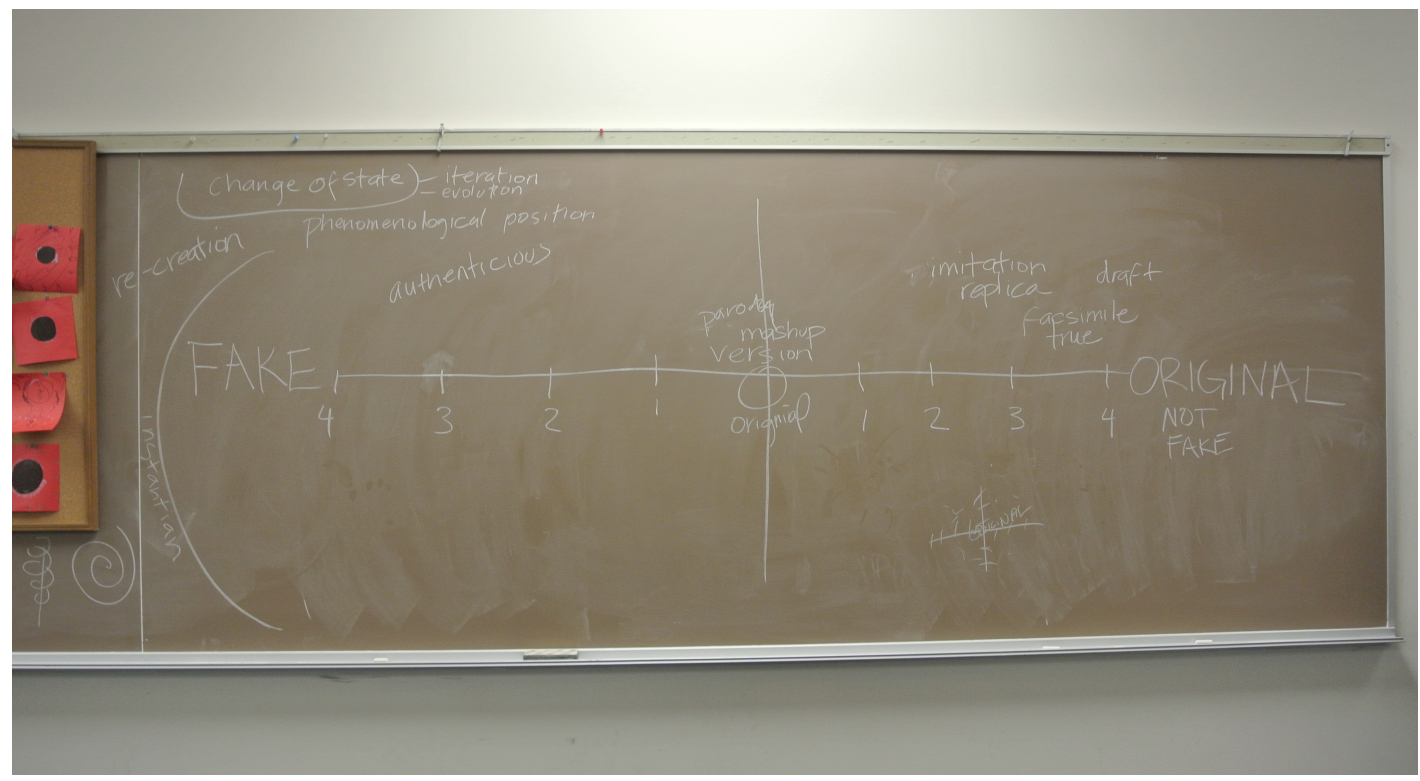

Although it was not a product of the participatory session itself, the Instantiation component found in the MuseLab on site at the conference (see Iannaggi \& Latham, this volume) can be seen as another product of this session (Figure 9). The label for this component, which was available for participants to view a full day before our session, read:

\section{Originals, copies, facsimiles and replicas}

A variety of objects representing the spectrum of representations, from copy to original (Mrs. Ples skull, Rosetta Stone, Two-headed calf, Liberty Bell, Painting on canvas, Paintings on balls)

"A copy of a fake of the identical facsimile reproduced from the real original" by K.F. Latham and Cori Iannaggi

Can a fake be original? Can a replica be real? What kind of representations are these objects on exhibit? Every day people use words such as copy, original, real, fake, actual, true, identical and more in reference to documents and their various representations. Do we need to clarify a terminology in order to communicate about these things? 
Figure 9. The (un)session's Instantiation exhibit.

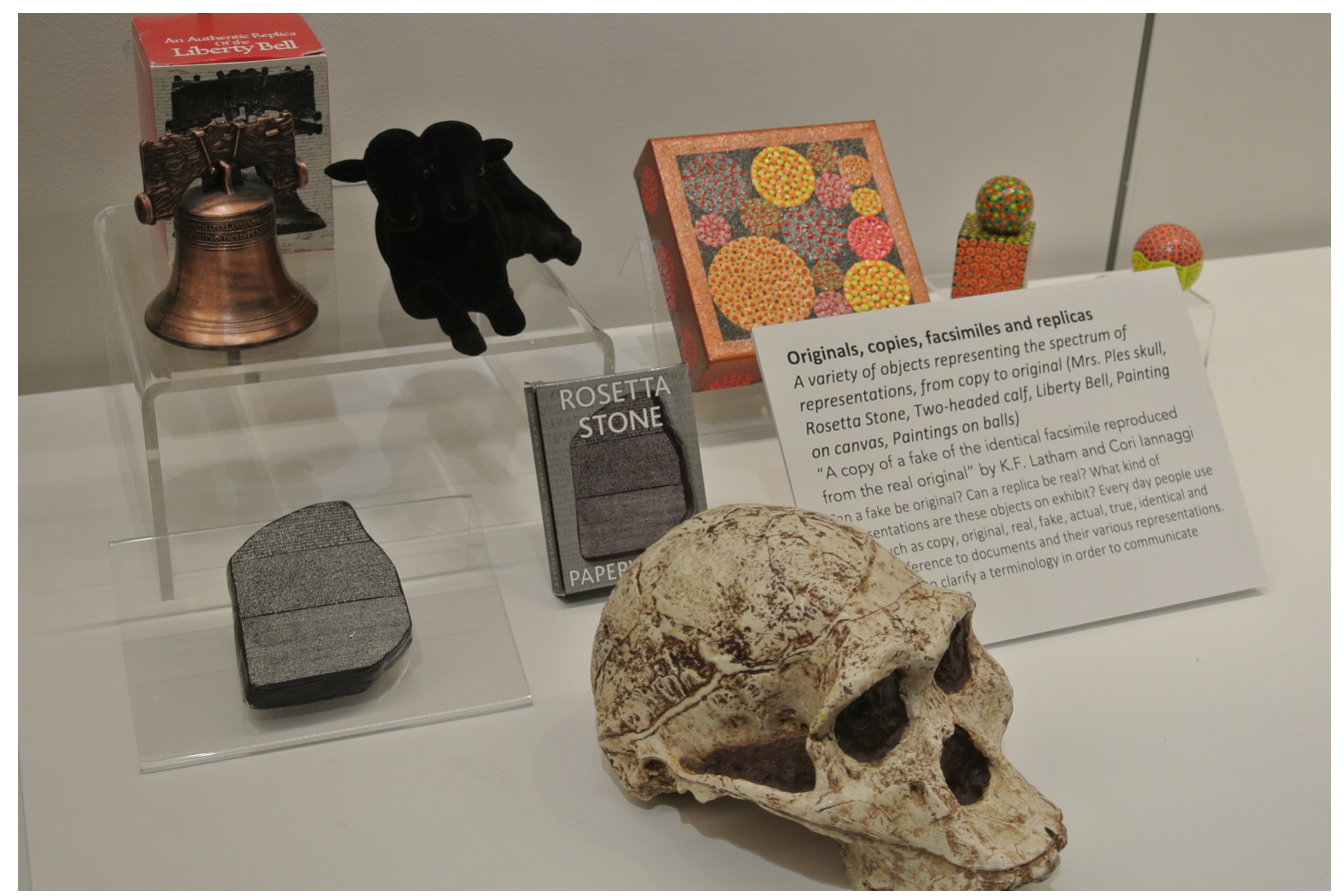

\section{The End, or The Beginning}

There is no formal conclusion for this paper. The (un)session we presented was meant to begin a conversation about the meaning and language of representing documents. The activities involving the word list and continuum made it even more obvious that the language we use to represent documents is diverse and signifies different meanings to different people. Taking into consideration the varying definitions of each word, creating a more intentional language may not be possible, but this session does reveal that it can't be assumed that we have clear meanings when using these words to describe documents.

Utilizing the unsession approach provided us with the opportunity to work through our ideas in a way that is typically not seen in a conference setting. We believe this style of presentation, one that promotes collaboration and conversation with the audience, can be useful to a researcher who wishes to further develop a new idea or for those seeking out the advice and expertise from their peers. 


\section{References}

Buckland, M. K. (1991). Information and information systems. New York:

Greenwood Press.

Davidson, Donald (2001 (1987)). "Knowing One's Own Mind." Reprinted in Subjective, Intersubjective, Objective (pp. 15-38). New York and Clarendon: Oxford University Press. Originally published in Proceedings and Addresses of the American Philosophical Association, 60 (1987), 441-58.

Follett, J. (2006, August 8). Understanding the unconference. Digital Web Magazine. Retrieved on September 1, 2014 at http://www digitalweb.com//articles/understanding_the_unconference

Greenhill, K., \& Wiebrands, C. (2008). The unconference: a new model for better professional communication. LIANZA.

Iannaggi, C.M. \& Latham, K.F. (2014). Instantiation: Academia's Pop-Up Museum. Proceedings from the Annual Meeting of the Document Academy, this volume.

Latham, K.F. \& Iannaggi, C.M. (2014). “A Copy of a Fake of the Identical Facsimile Reproduced from the Real Original". Document Academy 2014 Annual Meeting Program, Kent, OH.

Krulwich, R. \& Abumrad, J. (2014). Things. RadioLab Podcast. Retrieved from http://www.radiolab.org/story/things/

Robinson, W.H. (2014).Van Gogh Repetitions. Cleveland Art, (March/April), 4-5.

Wood, E. E., \& Latham, K. F. (2014). The Objects of Experience: Transforming visitor-object encounters in museums. Walnut Creek, CA.: Left Coast Press. 